\title{
Effect of Pharmacological Agents Administered for Attenuating the Extubation Response on the Quality of Extubation: A Systematic Review
}

\author{
Bushra Salim ${ }^{1}$, Saima Rashid ${ }^{1}$, M Asghar Ali ${ }^{1}$, Amir Raza ${ }^{1}$, Fauzia A. Khan ${ }^{1}$ \\ 1. Anaesthesiology, Aga Khan University, Karachi, PAK
}

Corresponding author: Bushra Salim, bushra.salim@aku.edu

\section{Abstract}

\section{Background}

Several drugs have been tried to obtund the hemodynamic extubation response but all have variable side effects that may affect the quality of short-term recovery.

\section{Objective}

Our primary objective was to evaluate the effect of pharmacological agents, such as dexmedetomidine, local anesthetics, and so on, administered for attenuating the extubation response on the quality of extubation, as judged by the presence or absence of cough, sedation, and laryngospasm/bronchospasm in adult patients who had undergone general anesthesia. A secondary objective was to evaluate the effect of these drugs on other immediate post-extubation complications such as respiratory depression, desaturation, bradycardia, hypotension, and nausea and vomiting (PONV).

\section{Methods}

This is a systematic review of (randomized controlled trials) RCTs with meta-analysis. The Medical Literature Analysis and Retrieval System Online (MEDLINE), Cumulative Index of Nursing and Allied Health Literature (CINAHL), and Cochrane Central Register of Controlled Trials (CENTRAL) databases were searched for RCTs on the effect of pharmacological agents on both the hemodynamic extubation response as well as the quality of extubation.

\section{Results}

Fourteen out of 24 included studies were subjected to a meta-analysis. The risk of cough was less likely in the intervention group as compared to control groups (OR $0.26,95 \%$ CI 0.15 to $0.46, \mathrm{p}<0.00001$, $\left.\mathrm{I}^{2}=35 \%\right)$. Sedation, hypotension $\left(\mathrm{OR}=10.47 ; 95 \% \mathrm{CI}: 1.86,58.80, \mathrm{p}=0.008, \mathrm{I}^{2}=0 \%\right)$, and bradycardia $(\mathrm{OR}=6.57$; $95 \%$ CI: $2.09,20.64, \mathrm{p}=0.001, \mathrm{I}^{2}=0 \%$ ) were reported with dexmedetomidine. Only one study reported

Received 11/18/2019 Review began 12/09/2019 Review ended 12/17/2019 Published 12/20/2019

○ Copyright 2019 Salim et al. This is an open access article distributed under the terms of the Creative Commons Attribution License CC-BY 3.0., which permits unrestricted use, distribution, and reproduction in any medium, provided the original author and source are credited.

\section{Conclusion}

Dexmedetomidine 0.4 to $0.5 \mathrm{ug} / \mathrm{kg}$ was associated with smooth extubation, minimal coughing, no laryngospasm/ bronchospasm, and with stable hemodynamics, without causing respiratory depression, PONV, and desaturation. However, in higher doses (more than $0.5 \mathrm{ug} / \mathrm{kg}$ ), it caused bradycardia, hypotension, and sedation. Other pharmacological agents, such as local anesthetics, calcium channel blockers, and opioids, did not attenuate cough associated with extubation.

Categories: Anesthesiology, Internal Medicine

Keywords: endotracheal extubation, complications, cough, dexmedetomidine, lidocaine, opioids

\section{Introduction}

Tracheal extubation following general anesthesia is associated with hemodynamic changes and airway reflexes [1]. The goals of smooth extubation are to avoid hemodynamic changes, minimize airway stimulation, and prevent straining, coughing, breath-holding, and laryngospasm, as well as to ensure continuous oxygen delivery to the lungs. Patients with cardiovascular and/or neurological diseases, active and passive smokers, and those with chronic airway diseases have a higher incidence of complications as related to extubation [1].

Several drugs have been investigated to obtund the hemodynamic extubation response in vulnerable patients. These are narcotics [2-3], local anesthetics [4], calcium channel blockers [5], alpha agonists, and so on [6-7]. All these pharmacological interventions are associated with certain undesirable side effects [4]. 
The rationale of this systematic review was to determine the effectiveness of the pharmacological agents administered for attenuating the hemodynamic extubation response with minimal effects on the quality of tracheal extubation.

\section{Objectives}

Our primary objective was to evaluate the effect of pharmacological agents administered for attenuating the tracheal extubation response on the quality of extubation as judged by the presence or absence of cough and/or sedation and the presence of laryngospasm/bronchospasm in adult patients undergoing general anesthesia. Our secondary objective was to evaluate the effect of these drugs on other, immediate postextubation complications such as respiratory depression, desaturation, bradycardia, hypotension, and nausea and vomiting.

\section{Materials And Methods}

\section{Design}

A systematic review of randomized controlled trials (RCTs) with a meta-analysis.

\section{Data sources}

The Medical Literature Analysis and Retrieval System Online (MEDLINE), Cumulative Index of Nursing and Allied Health Literature (CINAHL), and Cochrane Central Register of Controlled Trials (CENTRAL) databases were systematically searched for articles published between January 1, 1990, and December 31, 2015 (26 years).

The search strategy used and the keywords are provided in the appendix.

A bibliography of relevant articles was searched for additional studies and the search was not restricted by language. Authors of identified publications were not contacted for additional information.

\section{Eligibility criteria}

Inclusion Criteria

We included RCTs that studied the effect of pharmacological agents on both the hemodynamic extubation response as well as the quality of extubation. RCTs with both placebo and a drug control group, reporting on adult patients (18 years or above), of any race, either gender, and undergoing elective surgery in the operating room were included.

Studies that reported on any of the following primary or secondary outcomes were included.

Primary outcomes: The primary outcome was the quality of extubation. This was assessed by the presence or absence of cough at the time of extubation (graded from 1 to 5) [8], degree of sedation after extubation (Ramsay scale score of 1 and 2 meaning no sedation) [9-10], and the presence of laryngospasm/ bronchospasm at the time of extubation.

Secondary outcomes: The secondary outcome were respiratory depression (respiratory rate less than 10 breaths per minute), bradycardia (heart rate less than 60 beats per minute), hypotension (blood pressure less than $20 \%$ from the baseline), nausea and vomiting, desaturation (peripheral capillary oxygen saturation (SpO2) less than 92\%) and any other adverse effects of drugs used for the suppression of the hemodynamic extubation response.

Exclusion Criteria

Studies where different doses of routine anesthetic drugs were used, (induction agents, muscle relaxants or inhalation agents) for attenuating the hemodynamic response to extubation were excluded.

Studies of patients undergoing tracheal extubation outside the operating room were also excluded.

Screening and Study Eligibility

All abstracts were independently screened by two reviewers. The selected articles were again reviewed independently by two reviewers. Any disagreement was referred to the third reviewer. The reasons for the exclusion of studies were also noted.

\section{Data extraction and handling}

Data were extracted individually by two reviewers on a predesigned data extraction form. 
The risk of bias assessment was noted appropriately by the authors according to a standard description for each type of bias based on the Cochrane risk of bias tool [11]. Random sequence generation (selection bias), allocation concealment (selection bias), blinding of participants (performance bias), blinding of outcome assessment (detection bias), bias of incomplete outcome data (attrition bias), and selective reporting bias (reporting bias) were assessed. After an independent assessment and then comparison, any conflicts were resolved by a discussion with the third reviewer. The studies were categorized into good quality, fair quality, and poor quality according to the thresholds set for converting the Cochrane risk of bias tool to Agency for Health Care Research and Quality (AHRQ) standards [11].

\section{Statistical analysis}

Meta-analyses were performed using Review Manager, version 5 software (The Cochrane Collaboration, Oxford, UK). The rate of cough, hypotension, bradycardia and nausea/vomiting of the intervention and control groups were tabulated and presented graphically using forest plots. The Mantel-Haenszel (M-H) analysis method with the random-effects model was used to compute the effect size in terms of the odds ratio for dichotomous outcomes. The chi-square $(\pi 2)$ test and I2 were performed to observe variability in the intervention effect that was due to heterogeneity among studies.

\section{Results}

\section{Study selection}

Our literature search identified 33 abstracts through both a database and a manual search. After going through the full texts of the abstracts, nine were excluded, as they did not fulfill our inclusion criteria completely, hence, 24 studies were included in the qualitative analysis (Figure 1).

Figure 1: Flow chart of literature search and study selection

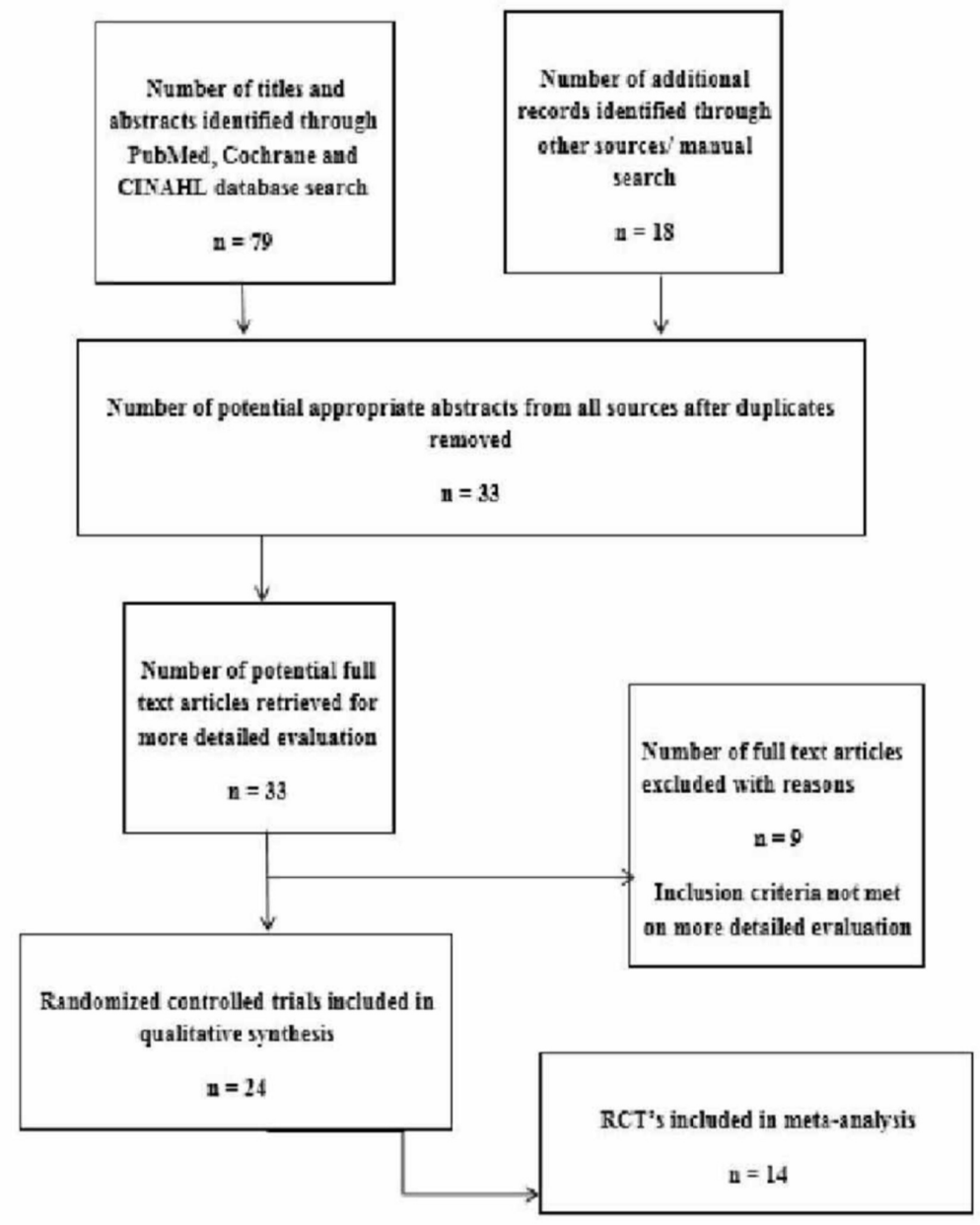

FIGURE 1: Flow chart of literature search and study selection 


\section{Cureus}

The data of all the study characteristics are shown in Table 1 .

\begin{tabular}{|c|c|c|c|c|c|c|}
\hline Author/Year & $\mathbf{N}$ & Study Groups & Dose & $\begin{array}{l}\text { Per Group } \\
\text { (n) }\end{array}$ & $\begin{array}{l}\text { Route of } \\
\text { Administration }\end{array}$ & Timing \\
\hline \multirow[t]{3}{*}{ Nishina 1995 [2] } & 60 & Saline & & 20 & Bolus & $\begin{array}{l}\text { At time of peritoneal } \\
\text { closure }\end{array}$ \\
\hline & & Fentanyl & 1 ug/kg & 20 & & \\
\hline & & Fentanyl & $2 \mathrm{ug} / \mathrm{kg}$ & 20 & & \\
\hline \multirow[t]{2}{*}{ Aksu 2009 [3] } & 40 & Dexmedetomidine & 0.5 ug/kg & 20 & Infusion & Before extubation \\
\hline & & Fentanyl & 1 ug/kg & 20 & & \\
\hline \multirow[t]{2}{*}{ Mistry 2016 [5] } & 30 & Verapamil & $0.1 \mathrm{mg} / \mathrm{kg}$ & 15 & IV Bolus/Infusion & On return of breathing \\
\hline & & Dexmedetomidine & $0.3 u g / k g$ & 15 & & \\
\hline \multirow[t]{5}{*}{ Kim 2015 [6] } & 115 & Saline & $0.1 \mathrm{ml} / \mathrm{kg} / \mathrm{hr}$ & $\begin{array}{l}28(a) \\
30(b)\end{array}$ & Infusion & $\begin{array}{l}\text { Drug given after } \\
\text { induction }\end{array}$ \\
\hline & & Dexmedetomidine & $0.4 \mathrm{ug} / \mathrm{kg} / \mathrm{hr}$ & $\begin{array}{l}27(a), \\
30(b)\end{array}$ & Infusion & \\
\hline & & Lidocaine & $1 \mathrm{mg} / \mathrm{kg}$ & 25 & I.V Bolus/Infusion & \\
\hline & & PG.E & $0.1 / \mathrm{mg} / \mathrm{kg}$ & 25 & Infusion & \\
\hline & & PG.L & $0.1 / \mathrm{mg} / \mathrm{kg}$ & 25 & Bolus + Infusion & \\
\hline \multirow[t]{3}{*}{ Xiaochun 2014 [7] } & 90 & Saline & & 30 & IV Bolus & $\begin{array}{l}30 \text { minutes after } \\
\text { intubation }\end{array}$ \\
\hline & & Dexmedetomidine & 0.4 ug/kg & 30 & IV Bolus & \\
\hline & & Dexmedetomidine & $0.8 \mathrm{ug} / \mathrm{kg}$ & 30 & IV Bolus & \\
\hline \multirow[t]{4}{*}{ Mikawa 1996 [12] } & 80 & Saline & & 20 & I.V/ Bolus & 3 min after reversal \\
\hline & & Diltiazem & $0.2 \mathrm{mg} / \mathrm{kg}$ & 20 & & \\
\hline & & Verapamil & $0.5 \mathrm{mg} / \mathrm{kg}$ & 20 & & \\
\hline & & Verapamil & $0.1 \mathrm{mg} / \mathrm{kg}$ & 20 & & \\
\hline \multirow[t]{4}{*}{ Nishina 1997 [13] } & 100 & Saline & $1 \mathrm{mg} / \mathrm{kg}$ & 25 & I.V & $2 \mathrm{~min}$ before extubation \\
\hline & & Lidocaine & $1 \mathrm{mg} / \mathrm{kg}$ & 25 & I.V Bolus/Infusion & \\
\hline & & PG.E & $0.1 / \mathrm{mg} / \mathrm{kg}$ & 25 & Infusion & \\
\hline & & PG.L & $0.1 / \mathrm{mg} / \mathrm{kg}$ & 25 & Bolus + Infusion & \\
\hline \multirow[t]{3}{*}{ Jee 2002 [14] } & 75 & Control & & 25 & IV Bolus & $\begin{array}{l}3 \text { to } 5 \mathrm{mIn} \text { before } \\
\text { extubation }\end{array}$ \\
\hline & & Lidocaine & $1 \mathrm{mg} / \mathrm{kg} 2 \%$ & 25 & IV Bolus & \\
\hline & & Lidocaine & $1 \mathrm{mg} / \mathrm{kg} 2 \%$ & 25 & Intra tracheally & \\
\hline \multirow[t]{2}{*}{ Guler 2005 [15] } & 60 & Dexmedetomidine & $0.5 \mathrm{mg} / \mathrm{kg}$ & 30 & I.V bolus & $\begin{array}{l}5 \text { min before end of } \\
\text { surgery }\end{array}$ \\
\hline & & Saline & & 30 & & \\
\hline \multirow[t]{2}{*}{ Mahoori 2014 [16] } & 50 & Saline & & 25 & Bolus & $\begin{array}{l}90 \mathrm{sec} \text { prior to } \\
\text { extubation }\end{array}$ \\
\hline & & Remifentanil & 0.2 ug/kg & 25 & Bolus & \\
\hline $\begin{array}{l}\text { Andrzejowski } \\
2002[17]\end{array}$ & 40 & Saline & $5 \mathrm{ml}$ & 20 & Tube cuff & $\begin{array}{l}\text { Insertion of first skin } \\
\text { clip }\end{array}$ \\
\hline
\end{tabular}




\section{Cureus}

\begin{tabular}{|c|c|c|c|c|c|c|}
\hline & & Lidocaine & $2 \% 5 \mathrm{ml}$ & 20 & Tube cuff & \\
\hline \multirow[t]{2}{*}{ Lee 2014 [18] } & 142 & Saline & & 71 & Infusion & After extubation \\
\hline & & Dexmedetomidine & 0.5 ug/kg & 71 & Infusion & \\
\hline \multirow[t]{2}{*}{ Shajar 1999 [19] } & 40 & Saline & & 20 & I.V/ Bolus & At time of last suture \\
\hline & & Remifentanil & $1 \mathrm{ug} / \mathrm{kg}$ & 20 & & \\
\hline \multirow[t]{3}{*}{$\begin{array}{l}\text { Moustafa } 2012 \\
\text { [20] }\end{array}$} & 60 & Lidocaine & $1.0 \mathrm{mg} / \mathrm{kg}$ & 20 & Bolus & 5 min before extubation \\
\hline & & Dexmedetomidine & $1 \mathrm{mg} / \mathrm{kg}$ & 20 & & \\
\hline & & Dexa +Lidocaine & $\begin{array}{l}0.1 \mathrm{ug} / \mathrm{kg}+1 \\
\mathrm{mg} / \mathrm{kg}\end{array}$ & 20 & & \\
\hline \multirow[t]{2}{*}{ Nho 2009 [21] } & 40 & Saline & & 20 & Infusion & 4 min post extubation \\
\hline & & Remifentanil & & 20 & & \\
\hline \multirow[t]{2}{*}{ Aouad 2009 [22] } & 60 & Saline & & 30 & Infusion & $\begin{array}{l}\text { At the end of the } \\
\text { surgery }\end{array}$ \\
\hline & & Remifentanil & $\begin{array}{l}1 / 10^{\text {th }} \text { dose of } \\
\text { infusion }\end{array}$ & 30 & Infusion & \\
\hline \multirow[t]{3}{*}{$\begin{array}{l}\text { Qing Fan } 2015 \\
\text { [23] }\end{array}$} & 74 & Sevoflurane-Remifentanil & $0.03 \mathrm{ug} / \mathrm{kg} / \mathrm{min}$ & 25 & Infusion & $\begin{array}{l}10 \text { min before } \\
\text { extubation }\end{array}$ \\
\hline & & $\begin{array}{l}\text { Sevoflurane- } \\
\text { Dexmedetomide SD5 }\end{array}$ & 0.5 ug/kg & 24 & & \\
\hline & & Sevoflurane & 0.7 ug/kg & 25 & & \\
\hline \multirow[t]{3}{*}{ Dutta 2016 [24] } & 45 & Saline & $10 \mathrm{ml}$ & 15 & Endotracheally & After last skin suture \\
\hline & & Lidocaine & $1.5 \mathrm{mg} / \mathrm{kg}$ & 15 & Endotracheally & \\
\hline & & Dexmedetomidine & 0.3 ug $/ \mathrm{kg}$ & 15 & IV & \\
\hline \multirow[t]{2}{*}{ Turan2008 [25] } & 40 & Saline & & 20 & $\begin{array}{l}\text { Bolus over } 60 \\
\text { second }\end{array}$ & $\begin{array}{l}5 \text { min before end of } \\
\text { procedure }\end{array}$ \\
\hline & & Dexmedetomidine & 0.5 ug/kg & 20 & $\begin{array}{l}\text { Bolus over } 60 \\
\text { second }\end{array}$ & \\
\hline \multirow[t]{3}{*}{ Sharma 2014 [26] } & 60 & Saline & $10 \mathrm{ml}$ & 20 & Bolus & Just before extubation \\
\hline & & Lidocaine & $1.5 \mathrm{mg} / \mathrm{kg}$ & 20 & Bolus & \\
\hline & & Dexmedetomidine & $0.5 \mathrm{ug} / \mathrm{kg}$ & 20 & Bolus & \\
\hline \multirow[t]{2}{*}{ Gao 2014 [27] } & 70 & Ropivaciane & $20 \mathrm{mg}$ & 35 & TCM & Before intubation \\
\hline & & Diacine & $20 \mathrm{mg}$ & 35 & TCM & \\
\hline \multirow[t]{2}{*}{ Kothari 2014 [28] } & 50 & Dexmedetomidine & $0.5 \mathrm{ug} / \mathrm{kg}$ & 25 & IV bolus & $\begin{array}{l}5 \text { minutes before } \\
\text { extubation }\end{array}$ \\
\hline & & Lignocaine & $1.5 \mathrm{mg} / \mathrm{kg}$ & 25 & & \\
\hline \multirow[t]{2}{*}{ Bindu 2013 [29] } & 50 & Saline & $100 \mathrm{ml}$ & 25 & I.V infusion & $\begin{array}{l}15 \text { min before } \\
\text { extubation }\end{array}$ \\
\hline & & Dexmedetomidine & $0.75 \mathrm{mcg} / \mathrm{kg}$ & 25 & I.V infusion & \\
\hline \multirow[t]{2}{*}{ Shruthi 2016 [30] } & 80 & Saline & $10 \mathrm{ml}$ & 40 & Infusion & $\begin{array}{l}\text { Beginning of skin } \\
\text { closure }\end{array}$ \\
\hline & & Dexmedetomidine & $0.5 \mathrm{ug} / \mathrm{kg}$ & 40 & Infusion & \\
\hline
\end{tabular}

TABLE 1: Characteristics of included studies 


\section{Cureus}

IV: intravenous; TCM: transcricoid membrane; N/S: normal saline; $\mathrm{n}$ : group sample size; $\mathrm{N}$ : total sample size; min: minutes

\section{Hemodynamic changes}

The hemodynamic response was reported as blood pressure (BP) and heart rate (HR) change in all trials but the manner of reporting was different among studies. Nine studies documented a change in systolic blood pressure (SBP), diastolic blood pressure (DBP), and HR [2-3,7,12-17] while 12 studies documented the changes in mean arterial pressure (MAP) and HR only [5-6,18-27]. Three studies documented changes in MAP in addition to SBP, DBP, and HR [28-30]. A saline control group was used in 18 studies [2,6-7,12-19,2122,24-26,29-30]. In four studies, no placebo was used in the control against the study drug [3,20,27-28]. In seven studies, the authors compared two different drugs or the same drug in different doses $[3,5,12,20,23,27-$ 28].

Hypotension was recorded in three studies [15,29-30] while bradycardia was observed in seven studies (see Table 2) $[3,5,15,18,26,29-30]$.

\begin{tabular}{|c|c|c|c|}
\hline Study ID Year & $\begin{array}{l}\text { Attenuation of } \\
\text { Haemodynamic } \\
\text { Response }\end{array}$ & Drug Groups & Comments \\
\hline Nishina 1995 [2] & Yes & Fentanyl Saline & $\begin{array}{l}\text { HR, SBP, DBP higher in the control group as compared to fentanyl } \\
(p<0.05)\end{array}$ \\
\hline Mikawa 1996 [12] & Yes & $\begin{array}{l}\text { Diltiazem, } \\
\text { Verapamil, } \\
\text { Saline }\end{array}$ & $\begin{array}{l}\text { HR, SBP, DBP. Both drugs attenuated but verapamil } 0.1 \mathrm{mg} / \mathrm{kg} \text { more } \\
\text { effective }\end{array}$ \\
\hline Nishina 1997 [13] & Yes & $\begin{array}{l}\text { Lidocaine, PGE, } \\
\text { PGE, Lidocaine } \\
\text { Saline }\end{array}$ & PGE, Lidocaine combination attenuated SBP, DBP, and HR $(p<0.05)$ \\
\hline Shajar 1997 [19] & Yes & $\begin{array}{l}\text { Remifentanil } \\
\text { Saline }\end{array}$ & $\begin{array}{l}\text { Remi attenuated both MAP, HR in comparison with saline }(p<0.01 \text { and } \\
0.05)\end{array}$ \\
\hline Jee 2002 [14] & Yes & Lidocaine Saline & $\begin{array}{l}\text { HR, SBP, DBP were attenuated by Lidocaine sprayed down the ETT } \\
\text { immediately after extubation only }\end{array}$ \\
\hline $\begin{array}{l}\text { Andrzejowski } 2002 \\
{[17]}\end{array}$ & No difference & Lidocaine Saline & No difference between the groups ( $p>0.05$ ) \\
\hline Guler 2005 [15] & Yes & Dex Saline & $\begin{array}{l}\text { SAP and DAP were significantly lower in the dex group compared to } \\
\text { saline }(p<0.05) \text {. Episode of bradycardia in } 1 \text { and hypotension in } 3 \\
\text { patients in the dex group }\end{array}$ \\
\hline Turan 2008 [25] & Yes & Dex Saline & $\begin{array}{l}\text { HR and MAP were significantly higher in control as compared to the dex } \\
\text { group }(p<0.01)\end{array}$ \\
\hline Aouad 2009 [22] & Yes & $\begin{array}{l}\text { Remifentanil } \\
\text { Saline }\end{array}$ & HR and MAP increased in control as compared to remi $(p<0.05)$ \\
\hline Nho 2009 [21] & Yes & $\begin{array}{l}\text { Remifentanil } \\
\text { Saline }\end{array}$ & $\begin{array}{l}\text { HR and MAP were significantly increased in the control group as } \\
\text { compared to remi (HR } p=0.001 \text { and MAP } p=0.002)\end{array}$ \\
\hline Aksu 2009 [3] & Yes & Dex Fentanyl & $\begin{array}{l}\text { HR, SBP, DBP were significantly increased by in fentanyl group as } \\
\text { compared to dex (HR } p=0.003 \text { and SBP } p=0.037)\end{array}$ \\
\hline $\begin{array}{l}\text { Moustafa } 2012 \\
{[20]}\end{array}$ & Yes & $\begin{array}{l}\text { Lidocaine Dex } \\
\text { Dex plus } \\
\text { lidocaine }\end{array}$ & $\begin{array}{l}\text { Dex+lidocaine combination attenuated HR, MAP, RPP in comparison to } \\
\text { the two drugs alone }(p<0.05)\end{array}$ \\
\hline Bindhu 2013 [29] & Yes & Dex Saline & $\begin{array}{l}\text { HR, SBP, DBP, and MAP significantly higher in control }(p<0.05) \text {. } \\
\text { Bradycardia and hypotension reported with dex }\end{array}$ \\
\hline Mahoori 2014 [16] & Yes & Dex Saline & HR, SBP, DBP were significantly increased in control $(p<0.05)$ \\
\hline Xiachun $^{7} 2014$ [7] & Yes & Dex Saline & $\begin{array}{l}\text { Dexmedetomidine } 0.8 \mathrm{ug} / \mathrm{kg} \text { more effectively attenuated HR, SBP, and } \\
\text { DBP }\end{array}$ \\
\hline & & Dex Lidocaine & edetomidine more effective than lignocaine in attenuating HR \\
\hline
\end{tabular}




\section{Cureus}

\begin{tabular}{|c|c|c|c|}
\hline Sharma 2014 [26] & Yes & Saline & $(p=0.01)$, MAP. One patient had bradycardia in the dex group \\
\hline Lee 2014 [18] & Yes & Dex Saline & $\begin{array}{l}\text { HR, MAP were attenuated in the dex group as compared to control. One } \\
\text { patient had bradycardia in the dex group }\end{array}$ \\
\hline Kothari 2014 [28] & Yes & Dex Lidocaine & $\begin{array}{l}\text { HR, SBP, DBP, MAP were below baseline in the dex group as } \\
\text { compared to the lido group }(p<0.05)\end{array}$ \\
\hline Gao 2014 [27] & Yes & $\begin{array}{l}\text { Ropivacaine } \\
\text { Diacine }\end{array}$ & HR, MAP Ropivaciane more effective than diacine ( $p<0.05)$ \\
\hline Fan 2015 [23] & Yes & $\begin{array}{l}\text { Remifentanil } \\
\text { Dex }\end{array}$ & HR, MAP. Dexmedetomidine more effective than remifentanil ( $p<0.05)$ \\
\hline $\mathrm{Kim}^{6} 2015$ [6] & Yes & Dex Saline & HR was lower in the dex group $(p<0.05)$, no difference in MAP \\
\hline Mistry 2016 [5] & Yes & Verapamil Dex & $\begin{array}{l}\text { HR, MAP were higher in the verapamil group than in the dex but } \\
\text { statistically insignificant }\end{array}$ \\
\hline Shruthi 2016c[30] & Yes & Dex Saline & $\begin{array}{l}\text { HR, SBP, DBP, MAP were lower in the dex group but significantly } \\
\text { increased in the control }(p<0.001)\end{array}$ \\
\hline Dutta $^{24} 2016$ [24] & Yes & $\begin{array}{l}\text { Lidocaine Dex } \\
\text { Saline }\end{array}$ & HR, MAP. Dexmedetomidine better effect than lignocaine spray $(p<0.05)$ \\
\hline
\end{tabular}

TABLE 2: Attenuation of hemodynamic response in the included studies

HR: heart rate; SBP: systolic blood pressure; DBP: diastolic blood pressure; MAP: mean arterial pressure

\section{Surrogate measures used for the quality of extubation and the immediate post-extubation complications}

The following outcome measures were used for assessing the quality of extubation and the immediate postextubation complications. The primary outcome measures were cough, sedation, and

laryngospasm/bronchospasm. The secondary outcome measures seen were hypotension, bradycardia, and immediate postoperative nausea and vomiting. The outcome measures are summarized in Table 3.

\begin{tabular}{|c|c|c|c|c|c|c|c|c|c|c|}
\hline \multirow{2}{*}{ Author/Year } & \multirow{2}{*}{ Study Groups } & \multirow{2}{*}{ Per Group (n) } & \multicolumn{3}{|c|}{ Primary Outcome (Event/n) } & \multicolumn{5}{|c|}{ Secondary Outcome (Event/n) } \\
\hline & & & Cough & Sedation & Laryngospasm & Hypotension & Desaturation & Bradycardia & Nausea/ vomiting & Respiratory depression \\
\hline \multirow[t]{3}{*}{ Nishina 1995 [2] } & Saline & 20 & 20/20 & Zero & Zero & Zero & Zero & Zero & $16 / 20$ & Zero \\
\hline & Fentanyl & 20 & 19/20 & Zero & Zero & Zero & Zero & Zero & 19/20 & Zero \\
\hline & Fentanyl & 20 & 17/20 & Zero & Zero & Zero & Zero & Zero & 19/20 & Zero \\
\hline \multirow[t]{4}{*}{ Mikawa 1996 [12] } & Saline & 20 & $3 / 20$ & $\mathrm{NR}$ & Zero & Zero & NR & Zero & NR & NR \\
\hline & Diltiazem & 20 & $3 / 20$ & NR & Zero & Zero & NR & Zero & NR & NR \\
\hline & Verapamil & 20 & $3 / 20$ & NR & Zero & Zero & NR & Zero & NR & NR \\
\hline & Verapamil & 20 & $3 / 20$ & NR & Zero & Zero & NR & Zero & NR & NR \\
\hline \multirow[t]{4}{*}{ Nishina $1997[13]$} & Saline & 25 & $25 / 25$ & NR & Zero & Zero & NR & Zero & NR & NR \\
\hline & Lidocaine & 25 & $13 / 25$ & NR & Zero & Zero & NR & Zero & NR & NR \\
\hline & PG.E & 25 & $25 / 25$ & NR & Zero & Zero & NR & Zero & NR & NR \\
\hline & PG.L & 25 & 14/25 & NR & Zero & Zero & NR & Zero & NR & NR \\
\hline \multirow[t]{2}{*}{ Shajar 1999 [19] } & Saline & 20 & $11 / 20$ & 10/20 & NR & zero & NR & Zero & 1 & Zero \\
\hline & Remifentanil & 20 & 9/20 & 3/20 & NR & zero & NR & Zero & 2 & Zero \\
\hline \multirow{2}{*}{ Jee 2002 [14] } & Saline & & $14 / 25$ & NR & Zero & NR & NR & NR & NR & NR \\
\hline & Lidocaine & 25 & $10 / 25$ & NR & Zero & $\mathrm{NR}$ & $\mathrm{NR}$ & NR & NR & NR \\
\hline
\end{tabular}




\section{Cureus}

\begin{tabular}{|c|c|c|c|c|c|c|c|c|c|c|}
\hline & Lidocaine & 25 & $11 / 25$ & NR & Zero & NR & NR & Non & NR & NR \\
\hline \multirow[t]{2}{*}{ Andrzejowski 2002 [17] } & Saline & 20 & Zero & NR & NR & Zero & NR & Zero & NR & NR \\
\hline & Lidocaine & 20 & Zero & NR & NR & Zero & NR & Zero & NR & NR \\
\hline \multirow[t]{2}{*}{ Guler 2005 [15] } & Dexmedetomidine & 30 & 3 & NR & Zero & 3 & Zero & 1 & NR & Zero \\
\hline & Saline & 30 & 8 & NR & Zero & Zero & Zero & Zero & $\mathrm{NR}$ & Zero \\
\hline \multirow[t]{2}{*}{ Turan 2008 [25] } & Saline & 20 & $4 / 20$ & NR & Zero & Zero & Zero & Zero & Zero & Zero \\
\hline & Dexmedetomidine & 20 & $0 / 20$ & NR & Zero & Zero & Zero & Zero & Zero & Zero \\
\hline \multirow[t]{2}{*}{ Aouad 2009 [22] } & Saline & 30 & $0 / 30$ & NR & Zero & Zero & Zero & Zero & NR & Zero \\
\hline & Remifentanil & 30 & $2 / 30$ & NR & Zero & Zero & Zero & Zero & NR & Zero \\
\hline \multirow[t]{2}{*}{ Nho 2009 [21] } & Saline & 20 & $8 / 20$ & $\mathrm{NR}$ & NR & Zero & Zero & Zero & $3 / 20$ & Zero \\
\hline & Remifentanil & 20 & $0 / 20$ & NR & NR & Zero & Zero & Zero & $0 / 20$ & Zero \\
\hline \multirow[t]{2}{*}{ Aksu 2009 [3] } & Dexmedetomidine & 20 & $1(5 \%)$ & 1 & Zero & Zero & Zero & $2 / 20$ & $2 / 20$ & NR \\
\hline & Fentanyl & 20 & $4(20 \%)$ & 2 & 1 & Zero & Zero & $2 / 20$ & $3 / 20$ & NR \\
\hline \multirow[t]{3}{*}{ Moustafa 2012 [20] } & Lidocaine & 20 & 5 & NR & NR & Zero & Zero & Zero & NR & NR \\
\hline & Dexmedetomidine & 20 & 14 & NR & NR & NR & Zero & NR & NR & NR \\
\hline & Dexmedetomidine + Lidocaine & 20 & 5 & NR & NR & NR & Zero & NR & NR & NR \\
\hline \multirow[t]{2}{*}{ Bindu 2013 [29] } & Saline & 25 & $21 / 25$ & $5 / 25$ & Zero & $0 / 25$ & Zero & $2 / 25$ & 2/25 & Zero \\
\hline & Dexmedetomidine & 25 & $4 / 25$ & $21 / 25$ & Zero & $2 / 25$ & Zero & $13 / 25$ & $1 / 25$ & Zero \\
\hline \multirow[t]{2}{*}{ Mahoori 2014 [16] } & Saline & 25 & $11 / 25$ & NR & 1 & Zero & Zero & Zero & NR & NR \\
\hline & Remifentanil & 25 & $6 / 25$ & NR & Zero & Zero & Zero & Zero & NR & NR \\
\hline \multirow[t]{3}{*}{ Xiaochun $2014[7]$} & Saline & 30 & Zero & Zero & NR & Zero & Zero & NR & Zero & NR \\
\hline & Dexmedetomidine & 30 & Zero & Zero & NR & Zero & NR & NR & Zero & NR \\
\hline & Dexmedetomidine & 30 & Zero & Zero & NR & Zero & NR & NR & Zero & NR \\
\hline \multirow[t]{3}{*}{ Sharma 2014 [26] } & Saline & 20 & $2 / 20$ & Zero & Zero & Zero & Zero & $0 / 20$ & NR & NR \\
\hline & Lidocaine & 20 & 0/20 & Zero & Zero & Zero & Zero & $0 / 20$ & NR & NR \\
\hline & Dexmedetomidine & 20 & $0 / 20$ & Zero & Zero & Zero & Zero & $1 / 20$ & NR & NR \\
\hline \multirow[t]{2}{*}{ Lee 2014 [18] } & Saline & 71 & $14 / 71$ & 3 & Zero & Zero & Zero & Zero & Zero & Zero \\
\hline & Dexmedetomidine & 70 & $5 / 70$ & 3 & Zero & Zero & Zero & $1 / 70$ & Zero & Zero \\
\hline \multirow[t]{2}{*}{ Kothari 2014 [28] } & Dexmedetomidine & 25 & Zero & $18 / 25$ & Zero & Zero & Zero & Zero & NR & Zero \\
\hline & Lignocaine & 25 & 5 & Zero & Zero & Zero & Zero & Zero & NR & Zero \\
\hline \multirow[t]{2}{*}{ Gao 2014 [27] } & Ropivaciane & 35 & $0 / 35$ & NR & NR & Zero & Zero & Zero & $2 / 35$ & Zero \\
\hline & Diacine & 35 & $4 / 35$ & NR & NR & Zero & Zero & Zero & $3 / 35$ & Zero \\
\hline \multirow[t]{3}{*}{ Qing Fan 2015 [23] } & Sevofflurane-Remifentanil & 25 & Zero & Zero & Zero & NR & Zero & NR & $12 / 25$ & NR \\
\hline & Sevoflurane-Dexmedetomide SD5 & 24 & Zero & Zero & $1(4.2)$ & Zero & $1(4.2)$ & NR & $4 / 25$ & NR \\
\hline & Sevoflurane-SD7 & 25 & Zero & Zero & Zero & Zero & Zero & NR & $4 / 25$ & NR \\
\hline \multirow[t]{2}{*}{ Kim 2015 [6] } & Saline & 28(a), 30(b) & NR & 1(a) 6 (b) & NR & Zero & NR & Zero & $11 / 28$ (a) $3 / 30$ (b) & NR \\
\hline & Dexmedetomidine & $27(\mathrm{a}), 30(\mathrm{~b})$ & NR & 13(a) 11 (b) & NR & Zero & NR & Zero & 9/27 (a) 2/30 (b) & NR \\
\hline \multirow[t]{2}{*}{ Mistry 2016 [5] } & Verapamil & 15 & Zero & Zero & Zero & Zero & NR & Zero & NR & NR \\
\hline & Dexmedetomidine & 15 & Zero & Zero & Zero & Zero & NR & $1 / 15$ & NR & NR \\
\hline Shruthi 2016 [30] & Saline & 40 & $12 / 40$ & Zero & Zero & $0 / 40$ & Zero & $0 / 40$ & NR & NR \\
\hline
\end{tabular}




\section{Cureus}

\begin{tabular}{|c|c|c|c|c|c|c|c|c|c|c|}
\hline & Dexmedetomidine & 40 & $2 / 40$ & Zero & Zero & $9 / 40$ & Zero & $2 / 40$ & NR & NR \\
\hline \multirow[t]{3}{*}{ Dutta 2016 [24] } & Saline & 15 & Zero & Zero & Zero & Zero & NR & Zero & NR & $\mathrm{NR}$ \\
\hline & Lidocaine & 15 & Zero & Zero & Zero & Zero & NR & Zero & NR & NR \\
\hline & Dexmedetomidine & 15 & Zero & Zero & Zero & Zero & NR & Zero & $\mathrm{NR}$ & NR \\
\hline
\end{tabular}

TABLE 3: Primary and secondary outcomes reported in the included studies

\section{Cough}

Cough was observed in 13 placebo-controlled studies [2,13-16,18-19,21-22,25-26,29-30], and all these studies were included in the meta-analysis. Overall, cough developed in $23.2 \%$ of patients in the intervention group and $42.6 \%$ in the control group. The risk of cough was less likely in the intervention group as compared to the control group (OR 0.26, 95\% CI 0.15 to $0.46, \mathrm{p}=0.00001$, I2=35\%) (Figure 2).

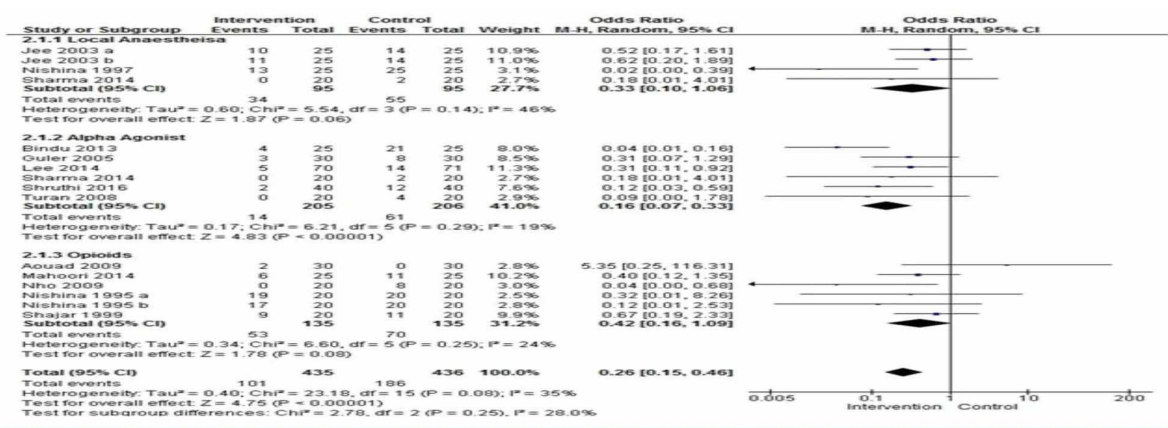

FIGURE 2: Comparison of incidence of cough between interventions vs. placebo

The odds ratio was calculated in the following subgroups.

Local Anesthetics Versus Placebo

Three studies compared lidocaine with placebo and were subjected to a meta-analysis [13-14,26]. There were 95 patients in each group, 34 developed a cough in the intervention group and 55 in the control group. The odds ratio was found to be 0.33 (95\% CI 0.10 - 1.06) $\mathrm{p}=0.06$ ) I2 $=46 \%$.

Alpha Agonist Versus Placebo

Six studies compared the alpha agonist with the placebo [15,18,25-26,29-30]. The incidence of cough was significantly reduced with alpha agonists. The odds ratio was 0.16 (95\% CI: $0.07,0.33) \mathrm{p}<0.00001) \mathrm{I} 2=19 \%$.

Opioids Versus Placebo

In five studies, the authors compared opioids with the placebo [2,16,19,21-22]. There was no statistical significance in the incidence of cough [OR=0.42 95\%CI: 0.16, 1.09; p=0.08, I2=24].

\section{Sedation}

Sedation was reported in 13 studies using the Ramsay scale [2-3,5-7,18-19,23-24,26,28-30]. These studies compared dexmedetomidine with remifentanil, verapamil, fentanyl, and lidocaine.

Alpha Agonists

Dexmedetomidine in different doses was compared to saline in seven studies [6-7,15,18,25,29-30]. The doses used were $0.4 \mathrm{ug} / \mathrm{kg}$ [6-7,18], $0.5 \mathrm{ug} / \mathrm{kg}$ [15,25,30], $0.75 \mathrm{ug} / \mathrm{kg}$ [29], and $0.8 \mathrm{ug} / \mathrm{kg}$ [7]. All the authors reported significantly higher sedation in the patient groups who were administered dexmedetomidine.

Dexmedetomidine $0.1 \mathrm{ug} / \mathrm{kg}$ resulted in a higher degree of sedation as compared to verapamil $0.3 \mathrm{ug} / \mathrm{kg}$ [5], but patients who received verapamil were anxious, agitated, and restless. The results were equivocal in 
studies that compared dexmedetomidine with lidocaine [24,26]. Dexmedetomidine in a dose of 0.3 and 0.5 $\mathrm{ug} / \mathrm{kg}$ as compared to lidocaine did not show a significant difference in sedation $[24,26]$. Two studies compared dexmedetomidine with opioids [3,23]. Dexmedetomidine $0.5 \mathrm{ug} / \mathrm{kg}$ was compared with fentanyl $1 \mathrm{ug} / \mathrm{kg}$. One patient in the dexmedetomidine group and two in the fentanyl group were not arousable [3]. Remifentanil $0.03 \mathrm{ug} / \mathrm{kg} / \mathrm{min}$ was compared with dexmedetomidine $0.5 \mathrm{ug} / \mathrm{kg}$ and $0.7 \mathrm{ug} / \mathrm{kg}$ [23]. Time to awakening was comparable in all the groups $\mathrm{p}=0.24$.

Opioids

Two studies compared opioids with the placebo [2,19]. Remifentanil $1 \mathrm{ug} / \mathrm{kg}$ was compared with saline. Only three patients were sedated in the remifentanil group as compared to saline where 10 patients had sedation, $\mathrm{p}=0.056$ [19]. Two doses of fentanyl $1 \mathrm{ug} / \mathrm{kg}$ and $2 \mathrm{ug} / \mathrm{kg}$ were compared with saline and none of the patients were moderately or severely sedated in any group [2].

\section{Laryngospasm/ bronchospasm}

Laryngospasm/bronchospasm was reported in three studies [3,16,23]. One study looked at the effect of dexmedetomidine $0.5 \mathrm{ug} / \mathrm{kg}$ and fentanyl $1 \mathrm{ug} / \mathrm{kg}$ before extubation and reported one episode of laryngospasm in the fentanyl group [3]. Another study compared the effect of remifentanil $0.2 \mathrm{ug} / \mathrm{kg}$ with saline and reported one episode of laryngospasm in the saline group [16]. Two different doses of dexmedetomidine 0.5 and $0.7 \mathrm{ug} / \mathrm{kg}$ were compared with remifentanil $0.03 \mathrm{ug} / \mathrm{kg} / \mathrm{min}$ in another study, resulting in one episode of laryngospasm in the $0.5 \mathrm{ug} / \mathrm{kg}$ dexmedetomidine group [23].

\section{Hypotension}

Hypotension was observed in three studies using alpha agonists [15,29-30]. Fourteen out of 95 patients had hypotension in the intervention group as compared to none in the control group. The odds ratio was 10.47 (CI: $1.86-58.80$ ) with a p-value of $0.008, \mathrm{I} 2=0 \%$ (Figure 3).

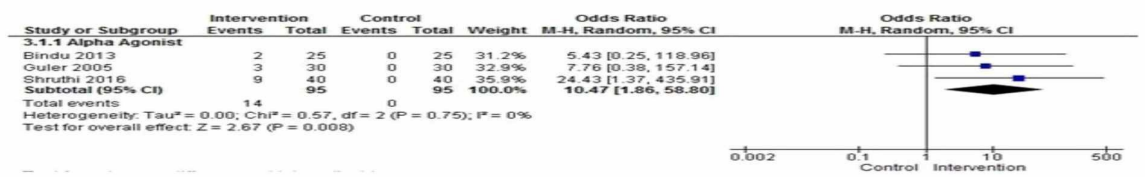

FIGURE 3: Comparison of the incidence of hypotension between interventions vs. placebo

\section{Bradycardia}

Five placebo-controlled studies using dexmedetomidine reported on bradycardia at extubation [15,18,26,29,30]. All reported bradycardia with dexmedetomidine. Eighteen events of bradycardia occurred in the intervention group as compared to two in the control group. The risk of bradycardia was about seven times more likely in the intervention group as compared to the control group [OR=6.57; 95\% CI: 2.09, 20.64, $\mathrm{p}=0.001, \mathrm{I} 2=0 \%$ ] (Figure 4).

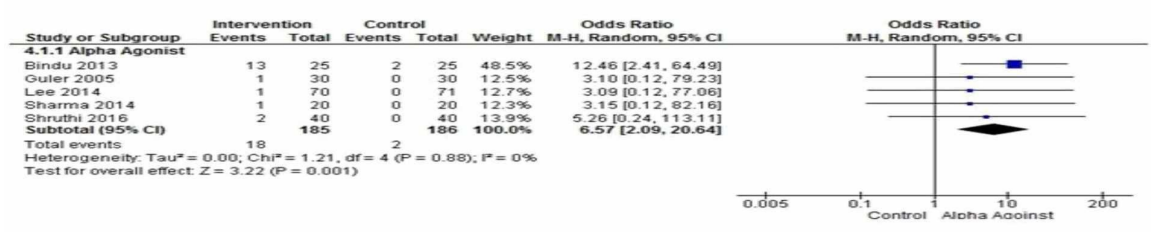

FIGURE 4: Comparison of the incidence of bradycardia between interventions vs. placebo

\section{Nausea and vomiting}

Five studies reported nausea and vomiting in the immediate postoperative period $[2,6,19,21,29]$. The combined effect was not statistically significant between groups [OR=1.03; $95 \% \mathrm{CI}: 0.48,2.25$, $\mathrm{p}=0.37$, I2 $=8 \%]$ (Figure 5). 


\section{Cureus}

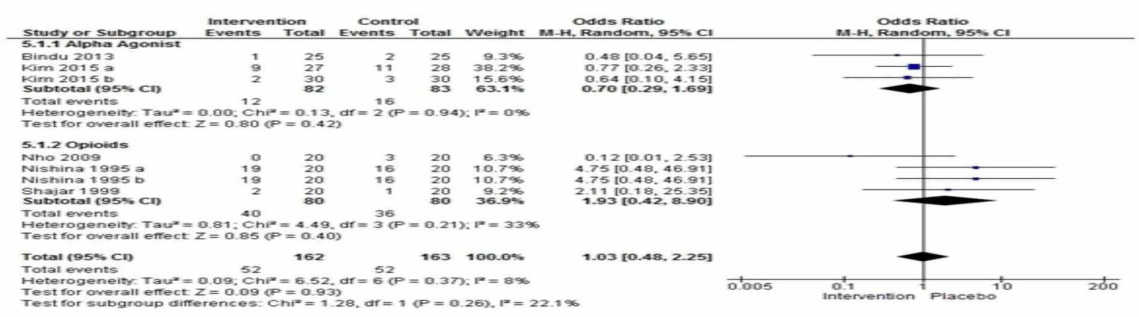

FIGURE 5: Comparison of the Incidence of Nausea or Vomiting Between Interventions vs. Placebo

Subgroup Analysis for Alpha Agonist and Opioid with Control

Nausea and vomiting were observed and reported in two studies using alpha agonists $[3,6]$ and three studies with opioids $[2,19,21]$.

In the subgroup analysis, the effect was not statistically significant between groups [OR $=0.70 ; 95 \% \mathrm{CI}: 0.29$, 1.68, $\mathrm{p}=0.42, \mathrm{I} 2=0 \%$ ] and $[\mathrm{OR}=1.93 ; 95 \% \mathrm{CI}: 0.42,8.90 ; \mathrm{p}=0.40, \mathrm{I} 2=33 \%]$.

Studies Not Subjected to the Meta-Analysis

Descriptive results

Studies with Local Anesthetics

Ropivacaine $1 \%$ was compared with diacine $1 \%$ via a transcricoid membrane injection. In the ropivacaine group, $91.9 \%(95 \% \mathrm{CI}=85.2-98.7 \%)$ patients did not experience any cough versus $46 \%$ (95\% CI=34.4-59.2\%) patients in the diacine group $(\mathrm{P}<0.05)[27]$.

The efficacy of $2 \%$ lidocaine administered through the tracheal tube in attenuating the extubation response in patients who were beta blocked with propranolol $1 \mathrm{mg} / \mathrm{kg}$ was compared with placebo, resulting in no difference between lidocaine and placebo in the degree of cough (p-value 0.4) [17].

Studies with Prostaglandins

Intravenous lidocaine $1 \mathrm{mg} / \mathrm{kg}$, prostaglandin E $0.1 \mathrm{ug} / \mathrm{kg}$, and a combination of lidocaine and prostaglandin $\mathrm{E}$ in the same dose were compared with placebo. Cough was reported in $52 \%$ of patients treated with lidocaine alone, 56\% with lidocaine prostaglandin E combination while in all patients in prostaglandin $\mathrm{E}$ group and placebo [13].

Studies with Alpha Agonists

No patient experienced cough with $0.8 \mathrm{ug} / \mathrm{kg}$ dexmedetomidine as compared to $3.3 \%$ of patients treated with $0.4 \mathrm{ug} / \mathrm{kg}$ dexmedetomidine. This study was in Chinese, and we were not able to get it translated into English; hence, the information presented here is taken from the abstract [7].

Three studies compared dexmedetomidine with lidocaine [24,26,28], the effect of intravenous dexmedetomidine $0.1 \mathrm{ug} / \mathrm{kg}$ was compared with lidocaine $1 \mathrm{mg} / \mathrm{kg}$ or their combination in the same dose [20]. Twenty-five percent of patients in the dexmedetomidine group and $5 \%$ in both the lidocaine and lidocaine with dexmedetomidine groups developed a severe cough.

Dexmedetomidine $0.3 \mathrm{ug} / \mathrm{kg}$ was compared with lidocaine $1.5 \mathrm{mg} / \mathrm{kg}$. The number of patients with no cough was $86.6 \%$ in the dexmedetomidine group compared to $60 \%$ in the lidocaine group $(\mathrm{P}=0.0087)$ [23].

Dexmedetomidine $0.5 \mathrm{ug} / \mathrm{kg}$ was compared with lidocaine $1.5 \mathrm{mg} / \mathrm{kg}$. Five patients (20\%) had a cough during extubation in the lidocaine group as compared to none in the dexmedetomidine group $(\mathrm{p}=<0.05)$ [28].

Dexmedetomidine $0.3 \mathrm{ug} / \mathrm{kg}$, when compared with verapamil $0.1 \mathrm{mg} / \mathrm{kg}$, [5] resulted in 12 (80\%) patients in the dexmedetomidine group with no cough while $9(60 \%)$ in the verapamil group had minimal coughing $(\mathrm{P}<0.0029)$.

Two studies compared dexmedetomidine with remifentanil and fentanyl [3,23]. Fan et al. compared two 


\section{Cureus}

different doses of dexmedetomidine, 0.5 and $0.7 \mathrm{ug} / \mathrm{kg}$, with remifentanil $0.03 \mathrm{ug} / \mathrm{kg} / \mathrm{min}$. Only two patients had moderate cough in the remifentanil group, four had moderate, and two had severe cough in the dexmedetomidine $0.5 \mathrm{ug} / \mathrm{kg}$ group while none had moderate to severe cough in the dexmedetomidine 0.7 $\mathrm{ug} / \mathrm{kg}$ group. One patient had laryngospasm in the dexmedetomidine 0.5 group [23]. Aksu et al. studied the effect of dexmedetomidine $0.5 \mathrm{ug} / \mathrm{kg}$ and fentanyl $1 \mathrm{ug} / \mathrm{kg}$. No patient had severe cough in the dexmedetomidine group while four had in the fentanyl group. Only one patient (5\%) had moderate cough in the dexmedetomidine group in contrast to four $(20 \%)$ in the fentanyl group ( $\mathrm{p}=0.003)$. One patient developed laryngospasm in the fentanyl group [3].

Studies with Narcotics

Nho et al. studied the effect of remifentanil infusion maintained at a target organ concentration of $1.5 \mathrm{ng} / \mathrm{ml}$ during emergence. Coughing was less frequent in the remifentanil group than in the control group. They did not give the numbers of patients who experienced cough neither the grade of cough [21].

Studies with Calcium Channel Blockers

Mikawa et al. studied the effect of two different doses of verapamil $0.05 \mathrm{ug} / \mathrm{kg}$ and $0.1 \mathrm{ug} / \mathrm{kg}$ with diltiazem $0.2 \mathrm{ug} / \mathrm{kg}$ and saline. They reported that all patients coughed with the extubation quality scores (median 3, range 2-5) being the same in all the four groups. No patient developed laryngospasm, hypotension, and bradycardia [12].

\section{Risk of bias across studies}

The quality of each study was assessed using the Cochrane risk of bias tool for RCTs [27]. This information is given in Table 4. 


\begin{tabular}{|c|c|c|c|c|c|c|c|c|}
\hline \multirow[b]{2}{*}{ Study ID } & \multicolumn{8}{|c|}{ Risk of Bias Assessment } \\
\hline & Year & $\begin{array}{l}\text { Random } \\
\text { Sequence } \\
\text { Generation }\end{array}$ & $\begin{array}{l}\text { Allocation } \\
\text { Concealment }\end{array}$ & $\begin{array}{l}\text { Plinding of } \\
\text { Participants and } \\
\text { Personnel }\end{array}$ & $\begin{array}{l}\text { Blinding of } \\
\text { Outcome } \\
\text { Assessment }\end{array}$ & $\begin{array}{l}\text { Incomplete } \\
\text { Outcome Data }\end{array}$ & $\begin{array}{l}\text { Selective } \\
\text { Outcome } \\
\text { Reporting }\end{array}$ & $\begin{array}{l}\text { Quality of } \\
\text { Studies }\end{array}$ \\
\hline Nishina [2] & 1995 & unclear & low & low & low & low & low & fair \\
\hline Mikawa [12] & 1996 & low & low & low & low & low & low & good \\
\hline Nishina [13] & 1997 & unclear & unclear & low & unclear & high & low & poor \\
\hline Shajar [19] & 1999 & low & low & low & low & low & low & good \\
\hline Jee [14] & 2002 & high & unclear & low & low & low & low & fair \\
\hline $\begin{array}{l}\text { Andrzejowski } \\
\text { [17] }\end{array}$ & 2002 & unclear & low & low & low & high & low & poor \\
\hline Guler [15] & 2005 & unclear & low & low & low & low & low & fair \\
\hline Turan [25] & 2008 & unclear & low & low & low & low & low & fair \\
\hline Aouad [22] & 2009 & low & low & low & low & low & low & good \\
\hline Nho [21] & 2009 & low & low & low & low & low & low & good \\
\hline Aksu $[3]$ & 2009 & unclear & low & low & low & low & low & fair \\
\hline $\begin{array}{l}\text { Moustafa } \\
\text { [20] }\end{array}$ & 2012 & unclear & unclear & low & low & low & Low & fair \\
\hline Bindu [29] & 2013 & low & unclear & low & low & low & low & fair \\
\hline Mahoori [16] & 2014 & low & unclear & low & low & unclear & low & poor \\
\hline $\begin{array}{l}\text { Zhoo } \\
\text { Xiaochun [7] }\end{array}$ & 2014 & low & low & low & low & low & low & good \\
\hline Sharma [26] & 2014 & Low & low & low & low & low & low & good \\
\hline Lee [18] & 2014 & low & low & low & low & low & low & good \\
\hline Kothari [28] & 2014 & Low & low & low & low & low & low & good \\
\hline Gao [27] & 2014 & low & unclear & low & low & high & low & poor \\
\hline Qing Fan [23] & 2015 & low & low & low & low & low & low & good \\
\hline $\operatorname{Kim}[6]$ & 2015 & low & unclear & low & unclear & low & Low & fair \\
\hline Mistry [5] & 2016 & low & low & low & low & low & low & good \\
\hline Shruthi [30] & 2016 & low & low & low & low & low & low & good \\
\hline Dutta [24] & 2016 & unclear & low & low & low & low & low & fair \\
\hline
\end{tabular}

TABLE 4: Quality assessment of selected studies

\section{Discussion}

The main findings of this review are that at tracheal extubation, dexmedetomidine significantly reduced the incidence of cough but caused hypotension and bradycardia. Local anesthetics and opioids did not cause hypotension and bradycardia at extubation but their effect on cough was equivocal. Nausea and vomiting were observed with opioids, but this was not statistically significant in comparison to saline. Patients who received dexmedetomidine had a higher Ramsay score in recovery when compared to local anesthetics while the results of opioids on sedation were equivocal.

Tracheal extubation is associated with cardiovascular as well as respiratory complications. Hemodynamic complications, such as hypertension may lead to an increase in intraocular and intracranial pressure, tachycardia, and dysrhythmias $[12,28]$. This can be hazardous in high-risk patients who have hypertension, 
coronary artery, and /or cerebrovascular disease due to an increase in myocardial oxygen demand, which can lead to further myocardial ischemia and infarction, pulmonary edema, and cerebrovascular hemorrhage $[4,6]$. Various drugs like beta-blockers, calcium channel blockers, vasodilators, lidocaine, and opioids have been used to attenuate this reflex sympathetic stimulation to extubation, with equivocal results and undesirable side effects like sedation, hypotension, bradycardia, nausea, and vomiting [26,29]. An ideal agent is the one that keeps blood pressure and heart rate stable and has no undesirable side effects. Hemodynamic response was attenuated significantly by all drugs used in all included studies.

Sedation, respiratory depression, agitation, and nausea and vomiting are not desirable during and after extubation. Excessive sedation can lead to respiratory depression and increases morbidity and length of stay in PACU [29]. Similarly, agitation in the postoperative period can be very unpleasant for the patient and can lead to hemodynamic compromise. The aim is to have a calm patient with stable hemodynamics in the recovery room.

Extubation can stimulate unwanted airway responses due to laryngeal and tracheal irritation leading to cough, laryngospasm, and bronchospasm. These airway and circulatory responses on extubation can lead to surgical bleeding, cardiovascular instability, and respiratory compromise [1]. The incidence of postextubation coughing reported in different studies was between $76 \%$ and $96 \%[1,4,6]$. Dexmedetomidine 0.5 $\mathrm{ug} / \mathrm{kg}$ showed a significant reduction in the incidence of cough after intraocular [15], intracranial [17], and spinal surgeries [24], hence improving the quality of extubation when compared to placebo. It also decreased the need for postoperative analgesia without increasing the duration of stay in recovery [21]. It may cause bradycardia and hypotension in a dose-dependent manner but without other side effects. The dose of dexmedetomidine most commonly used in studies was $0.5 \mathrm{ug} / \mathrm{kg}$ but favorable results were seen with doses as low as $0.3 \mathrm{ug} / \mathrm{kg}$ [5]. Doses higher than $0.5 \mathrm{ug} / \mathrm{kg}$ resulted in higher sedation scores when compared to placebo [7].

Lidocaine alone, given intravenously or intratracheally, failed to produce a favorable outcome on the quality of extubation $[24,28]$. Combination with other drugs, such as prostaglandin E1 and dexmedetomidine, gave better results. Intravenous lidocaine $1 \mathrm{mg} / \mathrm{kg}$, when used in combination with prostaglandin E1, resulted in good-quality extubation with minimal cough or strain [13]. Laryngotracheal instillation with $2 \%$ lidocaine did not produce any difference in the degree of coughing [17]. Only one study reported the use of $2 \%$ lidocaine $1 \mathrm{mg} / \mathrm{kg}$ spray down the endotracheal tube, which attenuated the airway circulatory reflexes when compared to lidocaine given intravenously in the same dose [14]. Dexmedetomidine and lidocaine in combination when administered intravenously resulted in a favorable quality of extubation when compared with dexmedetomidine $0.1 \mathrm{ug} / \mathrm{kg}$ alone [20].

Calcium channel blocker was not found to be effective in the attenuation of cough reflex irrespective of dose and drug used [12]. Short-acting opioids like remifentanil and fentanyl have been used for the suppression of cough reflex, with remifentanil having more favorable effects. Remifentanil infusion resulted in suppressing the cough reflex better than the placebo [21]. Remifentanil infusion has also been effectively used to blunt the cough reflexes after thyroidectomies and nasal surgeries [21-22]. When used in patients undergoing abdominal surgery, remifentanil had no significant difference compared to placebo [16]. This variation can be due to the difference in the type of surgery as well as the use of bolus versus infusion. Fentanyl in a 1 $\mathrm{ug} / \mathrm{kg}$ dose failed to suppress the cough reflex when compared with $0.5 \mathrm{ug} / \mathrm{kg}$ dexmedetomidine [3]. When given in a dose of $2 \mathrm{ug} / \mathrm{kg}$, fentanyl resulted in a lesser incidence of cough compared to $1 \mathrm{ug} / \mathrm{kg}$ but that was not statistically significant [2]. Nausea and vomiting were not significantly increased with any of the drugs used in the included studies. The majority of the included studies in this review were of good or fair quality with a low risk of bias. Only three studies had one or more criteria for a high risk of bias.

This review has some limitations. First, not all studies were placebo-controlled. There was heterogeneity among the studies (I2 for cough $=60 \%$ ). Another limitation was that the population included in most studies was the American Society of Anesthesiologists (ASA) I and II. Only three studies included ASA III patients and only one mentioned the associated co-morbidity present in the patients. The results, therefore, may not be extrapolated to patients with co-morbidity who are those actually at risk of having complications. Further work needs to be done with different doses of dexmedetomidine to recommend a dose attenuating the cough reflex but resulting in stable hemodynamics and a calm patient.

\section{Conclusions}

This meta-analysis results show that dexmedetomidine $0.4-0.5 \mathrm{ug} / \mathrm{kg}$ is associated with good-quality smooth extubation, minimal coughing, no laryngospasm/ bronchospasm, and a calm patient, with stable hemodynamics, without causing respiratory depression, nausea and vomiting, and desaturation. However, in higher doses of more than $0.5 \mathrm{ug} / \mathrm{kg}$, it can cause bradycardia, hypotension, and sedation. More studies are needed to find out the ideal dose to be used for the attenuation of extubation response without causing any untoward circulatory depression. Other pharmacological agents, such as local anesthetics, opioids, and calcium channel blockers, did not attenuate cough.

\section{Appendices}




\section{Cureus}

\section{PubMed search}

(extubation) OR (tracheal extubation) OR (airway extubation) OR (endotracheal extubation) OR (intratracheal extubation)) AND ((beta blocking drug*) OR (esmolol) OR (labetalol) OR (metoprolol) OR (propranolol) OR (local anesthetic) OR (lidocaine) OR (lignocaine) OR (xylocaine) OR (alpha 2 adrenergic receptor agonists) OR (dexmedetomidine) OR (clonidine) OR (calcium channel blockers) OR (calcium channel antagonist) OR (nicardipine) OR (diltiazem) OR (verapamil) OR (magnesium sulphate)) AND ((cough) OR (dyspnea) OR (apnea) OR (bronchospasm) OR (bronchial spasm) OR (bronchial hyper reactivity) OR (laryngospasm) OR (laryngismus) OR (vocal cord dysfunction) AND (breath holding) OR (propofol) OR (airway obstruction) OR (hypoventilation) OR (hypoxia) OR (hypoxemia) OR (respiratory depression))) AND (Randomized Controlled Trial [ptyp] AND ("1990/01/01"[PDAT]: "2016/12/31"[PDAT]) AND Humans [Mesh] AND adult [Mesh]) (77 items)

\section{CINAHL search}

Extubation, airway extubation, Esmolol or labetalol or metoprolol, or propranolol, or lidaocaine, or lignocaine, or xylocaine, or dexmedetomidine, or clonidine, or calcium channel antagonist or nicardipine, or diltiazem, or verapamil, or magnesium sulphate, or dyspnea, or bronchospasm, or laryngospasm or vocal cord dysfunction, or propofol or hypoventilation or hypoxemia, or respiratory depression.

\section{Cochrane database search}

Extubation, airway extubation, Esmolol or labetalol or metoprolol, or propranolol, or lidocaine, or lignocaine, or xylocaine, or dexmedetomidine, or clonidine, or calcium channel antagonist or nicardipine, or diltiazem, or verapamil, or magnesium sulfate, or dyspnea, or bronchospasm, or laryngospasm or vocal cord dysfunction, or propofol or hypoventilation or hypoxemia, or respiratory depression.

\section{Cough}

$1=$ no coughing

2=smooth extubation, minimal coughing

$3=$ moderate coughing

4=severe coughing

5=poor extubation, very uncomfortable (laryngospasm and coughing 10 times)

1 and 2 mean no coughing.

3,4 , and 5 are yes.

\section{Sedation score}

Ramsay Scale

$1=$ anxious or agitated and restless or both

$2=$ cooperative, oriented and tranquil

3=drowsy but responds to commands

4=asleep and brisk response to light glabella tap or loud auditory stimulus

5=asleep, sluggish response to light glabella tap or loud auditory stimulus

6=asleep and unarguable

1 and 2 mean no sedation.

3, 4, 5, and 6 mean yes.

\section{Laryngospasm/ bronchospasm}

$1=$ no spasm 
$2=$ spasm present

Respiratory depression: respiratory rate of less than 10 breaths per minute

Bradycardia: heart rate of less than $60 \mathrm{~b}$ per minute

Hypotension: blood pressure of less than $20 \%$ of baseline

\section{Nausea/vomiting}

$1=$ no nausea / vomiting

$2=$ nausea and vomiting present

Desaturation=oxygen saturation of less than $92 \%$ immediately after extubation.

\section{Thresholds for converting the Cochrane risk of bias tool to AHRQ Standards (good, fair, and poor)}

Good quality: All criteria met (i.e. low for each domain)

Fair quality: One criterion not met (i.e. high risk of bias for one domain) or two criteria unclear, and the assessment that this was unlikely to have biased the outcome, and there is no known important limitation that could invalidate the results

Poor quality: One criterion not met (i.e. high risk of bias for one domain) or two criteria unclear, and the assessment that this was likely to have biased the outcome, and there are important limitations that could invalidate the results

Poor quality: Two or more criteria listed as high or unclear risk of bias

\section{Additional Information \\ Disclosures}

Human subjects: All authors have confirmed that this study did not involve human participants or tissue. Animal subjects: All authors have confirmed that this study did not involve animal subjects or tissue. Conflicts of interest: In compliance with the ICMJE uniform disclosure form, all authors declare the following: Payment/services info: All authors have declared that no financial support was received from any organization for the submitted work. Financial relationships: All authors have declared that they have no financial relationships at present or within the previous three years with any organizations that might have an interest in the submitted work. Other relationships: All authors have declared that there are no other relationships or activities that could appear to have influenced the submitted work.

\section{References}

1. Hung NK, Wu CT, Chan SM, et al.: Effect on postoperative sore throat of spraying the endotracheal tube cuff with benzydamine hydrochloride, 10\% lidocaine, and 2\% lidocaine. Anesth Analg. 2010, 111:882-886.

2. Nishina K, Mikawa K, Maekawa N, Obara H: Fentanyl attenuates cardiovascular responses to tracheal extubation. Acta Anaesthesiol Scand. 1995, 39:85-89. 10.1111/j.1399-6576.1995.tb05597.x

3. Aksu R, Akin A, Biçer C, Esmaoğlu A, Tosun Z, Boyaci A: Comparison of the effects of dexmedetomidine versus fentanyl on airway reflexes and hemodynamic responses to tracheal extubation during rhinoplasty: double-blind, randomized, controlled study. Curr Ther Res. 2009, 70:209-220. 10.1016/i.curtheres.2009.06.003

4. Meng Y-F, Cui G-X, Gao W, Li Z-W: Local airway anesthesia attenuates hemodynamic responses to intubation and extubation in hypertensive surgical patients. Med Sci Monit Int Med J Exp Clin Res. 2014, 20:1518. 10.12659/MSM.890703

5. Mistry T, Purohit S, Arora G, Gill N, Sharma J: Attenuation of extubation responses: comparison of prior treatment with verapamil and dexmedetomidine. J Neuroanaesth Crit Care. 2016, 3:33-39. 10.4103/2348 0548.173234

6. Kim DJ, Kim SH, So KY, Jung KT: Effects of dexmedetomidine on smooth emergence from anaesthesia in elderly patients undergoing orthopaedic surgery. BMC Anesthesiol. 2015, 15:139. 10.1186/s12871-0150127-4

7. Zhao X, Tong D, Long B, Wu X: Effects of different doses of dexmedetomidine on the recovery quality from general anesthesia undergoing thyroidectomy [Article in Chinese]. Zhonghua Wei Zhong Bing Ji Jiu Yi Xue. 2014, 26:239-243. 10.3760/cma.j.issn.2095-4352.2014.04.008

8. Yamasaki H, Takahashi K, Yamamoto S, Yamamoto Y, Miyata Y, Terai T: Efficacy of endotracheal lidocaine administration with continuous infusion of remifentanil for attenuating tube-induced coughing during emergence from total intravenous anesthesia. J Anesth. 2013, 27:822-826. 10.1007/s00540-013-1627-3

9. Poropat F, Cozzi G, Magnolato A, et al.: Teaching pain recognition through art: the Ramsay-Caravaggio 
sedation scale. Ital J Pediatr. 2018, 44:20. 10.1186/s13052-018-0453-5

10. Devi Vankayalapati S, Ramsali V M, Dumpala S, Pasupuleti S: Effect of dexmedetomidine on haemodynamic and recovery responses during tracheal extubation: a randomized comparative study. J Evol Med Dent Sci. 2016, 5:2880-2883. 10.14260/jemds/2016/671

11. Higgins JPT, Altman DG, Sterne JAC: Assessing Risk of Bias in Included Studies . Cochrane Handbook for Systematic Reviews of Interventions. 2008. 187-241. 10.1093/aje/kwx344

12. Mikawa K1, Nishina K, Maekawa N, Obara H: Attenuation of cardiovascular responses to tracheal extubation: verapamil versus diltiazem. Anesth Analg. 1996, 82:1205-1210. 10.1097/00000539-19960600000018

13. Nishina K, Mikawa K, Takao Y, Shiga M, Maekawa N, Obara H: Prostaglandin E 1, lidocaine, and prostaglandin E 1-lidocaine combination for attenuating cardiovascular responses to extubation. Can J Anaesth. 1997, 44:1211-1214. 10.1007/BF03013348

14. Jee D, Park SY: Lidocaine sprayed down the endotracheal tube attenuates the airway-circulatory reflexes by local anesthesia during emergence and extubation. Anesth Analg. 2003, 96:293-297. 10.1213/00000539200301000-00058

15. Guler G, Akin A, Tosun Z, Eskitascoglu E, Mizrak A, Boyaci A: Single-dose dexmedetomidine attenuates airway and circulatory reflexes during extubation. Acta Anaesthesiol Scand. 2005, 49:1088-1091. 10.1111/j.1399-6576.2005.00780.x

16. Mahoori A, Noroozinia H, Hasani E, Karami N, Pashaei N, Hatami S: The effect of low-dose remifentanil on the hemodynamic responses of endotracheal extubation. Acta Med Iran. 2014, 52:844-847.

17. Andrzejowski J, Francis G: The efficacy of lidocaine administered via the LITATM tracheal tube in attenuating the extubation response in beta-blocked patients following craniotomy. Anaesthesia. 2002, 57:387-403. 10.1046/j.1365-2044.2002.2466_4.X

18. Lee JS, Choi SH, Kang YR, Kim Y, Shim YH: Efficacy of a single dose of dexmedetomidine for cough suppression during anesthetic emergence: a randomized controlled trial. Can J Anesth. 2015, 62:392-398. 10.1007/s12630-014-0295-6

19. Shajar MA, Thompson JP, Hall AP, Leslie NAP, Fox AJ: Effect of a remifentanil bolus dose on the cardiovascular response to emergence from anaesthesia and tracheal extubation. Br J Anaest. 1999, 83:654656. 10.1093/bja/83.4.654

20. Moustafa AM, Atalla H, Koptan HM: Comparison of dexmedetomidine, lidocaine, and their combination in attenuation of cardiovascular and catecholamine responses to tracheal extubation and anesthesia emergence in hypertensive patients. Res Opin Anesth Intensive Care. 2015, 2:1-6.

21. Nho JS, Lee SY, Kang JM, et al.: Effects of maintaining a remifentanil infusion on the recovery profiles during emergence from anaesthesia and tracheal extubation. Br J Anaesth. 2009, 103:817-821. 10.1093/bja/aep307

22. Aouad MT, Al-Alami AA, Nasr VG, Souki FG, Zbeidy RA, Siddik-Sayyid SM: The effect of low-dose remifentanil on responses to the endotracheal tube during emergence from general anesthesia. Anesth Analg. 2009, 108:1157-1160. 10.1213/ane.0b013e31819b03d8

23. Fan Q, Hu C, Ye M, Shen X: Dexmedetomidine for tracheal extubation in deeply anesthetized adult patients after otologic surgery: a comparison with remifentanil. BMC Anesthesiol. 2015, 15:106. 10.1186/s12871015-0088-7

24. Dutta D, Godara M, Purohit S, Kalra P, Sharma S, Gill N: Comparison of the effect of intravenous dexmedetomidine and lignocaine spray instilled into the endotracheal tube on extubation response in patients undergoing spine surgery. J Neuroanaesth Crit Care. 2016, 3:239-244. 10.4103/2348-0548.190070

25. Turan G, Ozgultekin A, Turan C, Dincer E, Yuksel G: Advantageous effects of dexmedetomidine on haemodynamic and recovery responses during extubation for intracranial surgery. Eur J Anaesthesiol. 2008Oct, 25:816-820. 10.1017/S0265021508004201

26. Sharma VB, Prabhakar H, Rath GP, Bithal PK: Comparison of dexmedetomidine and lignocaine on attenuation of airway and pressor responses during tracheal extubation. J Neuroanaesthesiol Crit Care. 2014, 1:50-55. 10.4103/2348-0548.124850

27. Gao W, Xi JH, Ju NY, Cui GX: Ropivacaine via trans-cricothyroid membrane injection inhibits the extubation response in patients undergoing surgery for maxillary and mandibular fractures. Genet Mol Res. 2014, 13:1635-1642.

28. Kothari D, Tandon N, Singh M, Kumar A: Attenuation of circulatory and airway responses to endotracheal extubation in craniotomies for intracerebral space occupying lesions: dexmedetomidine versus lignocaine. Anesth Essays Res. 2014, 8:78-82. 10.4103/0259-1162.128916

29. Bindu B, Pasupuleti S, Gowd UP, Gorre V, Murthy RR, Laxmi MB: A double blind, randomized, controlled trial to study the effect of dexmedetomidine on hemodynamic and recovery responses during tracheal extubation. J Anaesthesiol Clin Pharmacol. 2013, 29:162-167. 10.4103/0970-9185.111665

30. Shruthi AH, Nethra SS, Sudheesh K, Devika DR, Raghavendra RSR: Effect of dexmedetomidine on hemodynamic parameters during extubation. A prospective randomized double blind study. Middle East J Anaesthesiol. 2016, 23:457-463. 